\title{
New approaches to symptomatic treatments for Alzheimer's disease
}

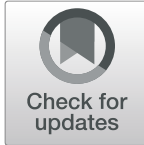

Jeffrey Cummings (1D

\begin{abstract}
Background: Successful development of agents that improve cognition and behavior in Alzheimer's disease (AD) is critical to improving the lives of patients manifesting the symptoms of this progressive disorder.

Discussion: There have been no recent approvals of cognitive enhancing agents for AD. There are currently 6 cognitive enhancers in Phase 2 trials and 4 in phase 3. They represent a variety of novel mechanisms. There has been progress in developing new treatments for neuropsychiatric symptoms in $A D$ with advances in treatment of insomnia, psychosis, apathy, and agitation in AD. There are currently 4 AD-related psychotropic agents in Phase 2 trials and 7 in Phase 3 trials. Many novel mechanisms are being explored for the treatment of cognitive and behavioral targets. Progress in trial designs, outcomes measures, and population definitions are improving trial conduct for symptomatic treatment of $A D$.

Conclusions: Advances in developing new agents for cognitive and behavioral symptoms of AD combined with enhanced trial methods promise to address the unmet needs of patients with AD for improved cognition and amelioration of neuropsychiatric symptoms.
\end{abstract}

Keywords: Neuropsychiatry, Alzheimer's disease, Psychosis, Apathy, Agitation, Depression, Drug development, Clinical trials, Cognition

\section{Background}

Alzheimer's disease $(\mathrm{AD})$ is a progressive neurodegenerative disorder manifested by cognitive and functional decline and the emergence of neuropsychiatric symptoms. The underlying biology of $\mathrm{AD}$ includes aggregation of soluble amyloid species into insoluble amyloid plaques, hyperphosphorylation of tau with formation of intracellular neurofibrillary tangles, and neuronal death along with a variety of related processes including neuroinflammation, synaptic and circuit dysfunction, mitochondrial and bioenergetic disorders, epigenetic changes, and vascular abnormalities $[1,2]$. Neuronal loss in

Correspondence: jcummings@cnsinnovations.com

For: "AD: Challenges for the Next Decade", organized by Drs. Todd Golde,

Alison Goate, and Guojun Bu as the lead editors. The series is to be published in Molecular Neurodegeneration in 2020-2021.

Chambers-Grundy Center for Transformative Neuroscience, Department of Brain Health, School of Integrated Health Sciences, University of Nevada Las Vegas, Las Vegas, NV, USA

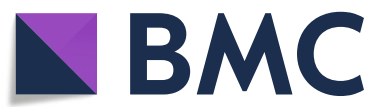

transmitter system source nuclei leads to neurochemical deficits that contribute to cognitive and behavioral symptoms [3].

All currently approved treatments for AD are "symptomatic" agents that aim to improve cognitive and behavioral symptoms without altering the underlying course of the disease [4]. Most current drug development programs target disease modification with agents that will prevent or delay the onset or slow the progression of $\mathrm{AD}$ [5]. No new therapies for $\mathrm{AD}$ have been approved by the US Food and Drug Administration (FDA) since 2003 and there are no approved therapies for disease modification of any adult-onset neurodegenerative disorder [5, 6]. Development of symptomatic agents is important; improvement in cognition is a key goal for patients with cognitive impairment, while relief of behavioral symptoms impacts quality of life of patients and caregivers and delays institutionalization. This review

(c) The Author(s). 2021 Open Access This article is licensed under a Creative Commons Attribution 4.0 International License, which permits use, sharing, adaptation, distribution and reproduction in any medium or format, as long as you give appropriate credit to the original author(s) and the source, provide a link to the Creative Commons licence, and indicate if changes were made. The images or other third party material in this article are included in the article's Creative Commons licence, unless indicated otherwise in a credit line to the material. If material is not included in the article's Creative Commons licence and your intended use is not permitted by statutory regulation or exceeds the permitted use, you will need to obtain permission directly from the copyright holder. To view a copy of this licence, visit http://creativecommons.org/licenses/by/4.0/ The Creative Commons Public Domain Dedication waiver (http://creativecommons.org/publicdomain/zero/1.0/) applies to the data made available in this article, unless otherwise stated in a credit line to the data. 
summarizes current cognitive enhancing approaches and addresses trends in the development of new symptomatic agents for the treatment of cognitive and behavioral abnormalities of AD. New directions in the treatment of cognitive enhancing agents are presented, and advances in the development of new therapies for neuropsychiatric and behavioral symptoms are discussed.

\section{Review}

Cognitive enhancing agents for treatment of Alzheimer's disease

\section{Current symptomatic therapies}

Four cholinesterase inhibitors (ChE-Is) and one Nmethyl-D-aspartate (NMDA) receptor antagonist have been approved by the FDA for the treatment of $\mathrm{AD}$. One ChE-I -.- tacrine -.- is no longer available on the market; the three available ChE-Is are donepezil (Aricept $^{\mathrm{Tm}}$ ), rivastigmine $\left(\right.$ Exelon $^{\mathrm{Tm}}$ ), and galantamine (Razadyne $\left.^{\mathrm{rw}}\right)$. The NMDA receptor antagonist is memantine $\left(\right.$ Namenda $\left.^{\mathrm{Tu}}\right)$. Clinical trials show that these agents produce improvement on the AD Assessment Scale - cognitive subscale (ADAS-cog) in the range of 1.5 to 3 points (of 70) with corresponding changes on the Mini Mental State Examination (MMSE) [7, 8]. Meta-analyses demonstrate consistent benefit compared to placebo on measures of function and global ratings [9]. Drugplacebo differences persist for a least 1 year in doubleblind trials [10]. Cholinesterase inhibitors and memantine have similar effects with improvements above baseline on measures of cognition and global function and temporary stabilization of activities of daily living (ADL). Most studies show amelioration of current neuropsychiatric symptoms with reduced emergence of new neuropsychiatric symptoms following treatment with symptomatic agents $[4,11,12]$.

ChE-Is capitalize on the unique biological circumstance in $\mathrm{AD}$ of loss of presynaptic cholinergic cells in the nucleus basalis of Meynert with preserved postsynaptic cortical cholinergic neurons, creating the opportunity for functional post-synaptic stimulation producing cholinergic augmentation with corresponding cognitive improvement $[13,14]$. The nucleus basalis provides the principal source of acetylcholine for the cerebral cortex and amygdala. Limbic and paralimbic cortices of the brain receive the most cholinergic input and are also the principal sources of reciprocal cortical projections back to the nucleus basalis [15]. No other transmitter system essential to cognition is known to have the pre/post-synaptic disconnection characteristic of the muscarinic cholinergic system, and this may explain in part the many failures to produce cognitive enhancement through stimulation of other transmitter systems.
Cognition is dependent on intact circuit function that includes cholinergic innervation as well as involvement of other transmitters. Imaging investigations such as those with functional magnetic resonance imaging (fMRI) and fluorodeoxyglucose (FDG) positron emission tomography (PET) typically show enhanced cortical circuit activity following treatment with ChEIs $[16,17]$. Enhancement of circuit function is a goal of cognitive-enhancing therapies and new imaging tools may assist in the search for more effective treatments [18].

\section{Clinical trial methodology for symptomatic cognitive enhancing agents}

The clinical methodology and instrumentation for $\mathrm{AD}$ trials was defined by trials of tacrine, the first agent approved for the treatment of AD by the FDA $[19,20]$. Patients were selected using the MMSE [21], and outcomes included the Clinical Global Impression of Change (CGIC) [22] and the ADAS-cog [23]. The approval process was based on draft guidelines from the FDA requiring that antidementia agents show improvement on dual outcomes: 1) the core symptoms of AD -.memory and cognition -.- and; 2) a global or a functional rating establishing that the effect was clinically meaningful [24]. This approach to AD clinical trials remains highly influential for trials of both putative cognitive enhancing and disease modifying therapies (DMTs). In most current trials, participants are defined by MMSE score range; the ADAS - cognitive subscale (ADAS-cog) is a commonly used outcome instrument in clinical trials for patients with AD dementia; and the CGIC or modified versions of the instrument are used in most trials of cognitive enhancing and behavioral agents being developed for AD. Nearly all trials of cognitive enhancing agents in AD dementia have used the "tacrine formula" for clinical trials with limited implementation of new instruments and measures in trials of patients with mildmoderate AD.

\section{Overview of recent trials for cognitive enhancing agents}

Figure 1 shows the clinical trial activity for cognitive enhancing agents from 2016 to 2020. Phase 2 and Phase 3 are shown. The data are derived from annual reviews of the AD drug development pipeline based on clinicaltrials.gov [5, 25-28]. There are more agents in Phase 2 than in Phase 3 for all years. Many agents are not advanced to Phase 3 after a failure to show a drug-placebo difference in Phase 2. There are fewer agents in Phase 3 in 2020 than in any previous year; the number of agents in Phase 2 varies and does not predict the number of agents in Phase 3 at later time points. 


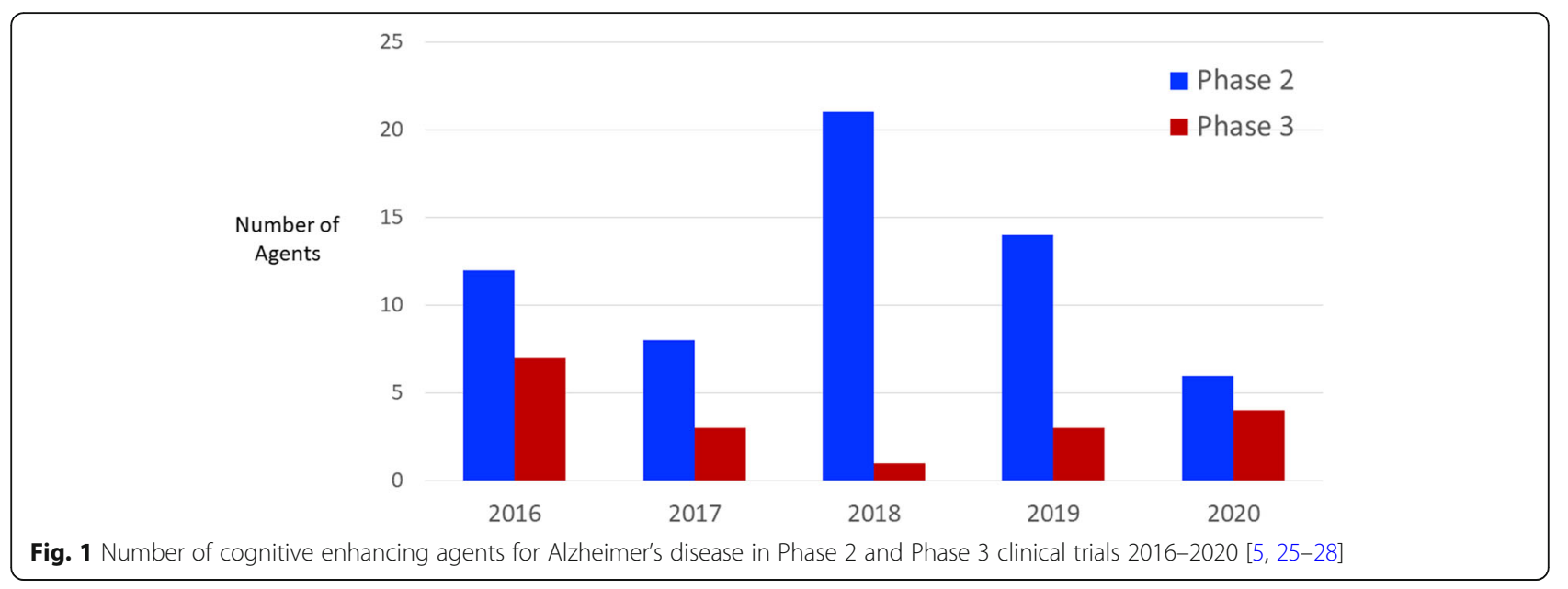

\section{Cognitive enhancing drugs with novel mechanisms of action in clinical trials}

GV-971 (Oligomannate ${ }^{\mathrm{m}}$ ) is an oligosaccharide that has putative effects on the gut microbiome to reduce systemic inflammation and neuroinflammation [29]. In a 9 month trial conducted in China, participants evidenced a significant improvement above baseline on the ADAS$\operatorname{cog}$ and showed a trend for improvement on the Clinical Interview Based Impression of Change with caregiver input $(\mathrm{CIBIC}+)$. These observations were sufficient for approval by the National Medical Products Administration (NMPA; Chinese equivalent of the FDA). GV-971 is the first drug treatment for $\mathrm{AD}$ approved anywhere in the world since 2003. The trial did not include biomarkers that might provide insight into the mechanism(s) of action of GV-971. The agent is being assessed in a global Phase 3 trial with clinical measures and biomarker outcomes to assess symptomatic and disease-modifying effects. Neuroinflammation is increasingly recognized as a key aspect of the pathogenesis of $\mathrm{AD}$ and an important target for drug development [30]. Dysbiosis of the gut microbiome in AD leads to local and systemic inflammation, release of neuroactive products that promote neuroinflammation, and perturbation of the normal gutbrain axis [31]. GV-971 reverses gut dysbiosis and reduces systemic inflammation in experimental AD model animals [19].

$5-\mathrm{HT}_{6}$ antagonists have been the subject of several recent clinical trials. Intepirdine, idalopirdine, and masuperdine are drugs in this class assessed in Phase 3 development programs [32]. All trials have failed to establish a drug-placebo difference on cognitive outcomes. Secondary behavioral outcomes in the masuperdine trial suggested a benefit on agitation and further assessment of the behavioral effects of this agent will be pursued. 5$\mathrm{HT}_{6}$ receptors are exclusively found in the central nervous system where they modulate primarily gammaaminobutyric acid (GABA) and glutamate levels, facilitating the secondary release of other neurotransmitters including noradrenaline and acetylcholine which are compromised in $\mathrm{AD}$ [33].

Cholinergic stimulation can be achieved with nicotinic cholinergic agonists or muscarinic cholinergic agonists in addition to the currently approved ChE-Is. Although promising results have been observed in early stage trials with these agents, none have succeeded in late stage trials or been approved by the FDA [34]. A nicotine transdermal patch is currently in a Phase 3 trial. Nicotinic receptors ( $\alpha 4 \beta 2$ subtype) are reduced in $\mathrm{AD}$ as demonstrated by the receptor-specific PET ligand 18F-flubatine [35].

New versions of ChE-Is are in development programs including octohydroaminoacridine and AD-35 [5].

ChE-Is in combination with peripheral cholinergic receptor blockers have been tested in an attempt to achieve greater central cholinergic stimulation while limiting peripheral cholinergic side effects. CPC-201 is an example of this strategy [36]. These approaches capitalize on the validated cognitive improvements demonstrated with ChE-Is.

A trial of MK-7622, an M1 positive muscarinic allosteric modulator, was stopped for futility and showed no drug-placebo differences on cognitive or functional outcomes [37]. Other members of this class may be explored given the evidence supporting cognitive and behavioral effects of these agents as well as a possible effects on the underlying pathobiology of $\mathrm{AD}[38,39]$.

The adrenergic system is a target of putative cognitive enhancing agents. Guanfacine is an alpha-2 adrenergic agonist currently in trials. The locus coeruleus and associated adrenergic projections to cerebral cortical regions mediating key aspects of cognition and behavior are atrophic in $\mathrm{AD}$ making adrenergic function a candidate for AD therapy [40].

The dopaminergic system may play a role in cognitive function, especially executive measures mediated by 
frontal-subcortical systems. The dopaminergic midbrain is altered in $\mathrm{AD}$ and substantial evidence links this structure to the cognitive and behavioral changes of $\mathrm{AD}$ [41]. Rotigotine, a dopamine agonist approved for the treatment of motor symptoms of Parkinson's disease, showed a benefit on frontal-executive measures in a Phase 2 trial for AD [42]. Rasagiline, a monoamine oxidase inhibitor approved for motor symptoms of Parkinson's disease, improved metabolism on FDG PET in an AD trial and produced benefit on some executive measures and a quality of life scale without improving performance on memory measures [43]. Ladostigil, a multi-target agent with ChE-I and monoamine oxidase inhibition properties, did not improve cognition or delay decline in a Phase 2 trial [44]. Sembragiline, another monoamine oxidase inhibitor, showed no drug-placebo difference in a 12 month Phase 2 trial; patients on active treatment had reduced behavioral symptoms compared to those on placebo [45].

Phosphodiesterase inhibitors (PDE-Is) are another class of agents which have been assessed in multiple $\mathrm{AD}$ clinical trials, so far without successfully demonstrating a drug-placebo difference in cognition (Table 1). In many cases, the phosphodiesterase inhibitors have multiple targets with cognitive enhancement being among the potential outcomes and disease modification another potential treatment benefit. Inhibitors of PDE 3, 4, 5 and 9A have been assessed in clinical trials; some PDE inhibitors remain in trials and may ultimately demonstrate a significant cognitive benefit. Phosphodiesterase inhibitors enhance cyclic adenosine monophosphate (cAMP) and/or cyclic guanosine monophosphate (cGMP) signaling by inhibiting degradation of these cyclic nucleotides. cAMP and cGMP signaling are essential in a variety of cellular functions, including neuroplasticity and neuroprotection, and PDEs are increasingly receiving attention as possible targets for treatment of AD [46]. cGMP can be measured in cerebrospinal fluid (CSF) as a target engagement biomarker in human trials of some PDE-Is [47].

$\mathrm{Xanamem}^{\circ}(\mathrm{UE} 2343)$ is a an 11-ß-hydroxysteroid dehydrogenase (HSD) antagonist intended to produce cognitive enhancement through blocking the adverse effects of endogenous glucocorticoids on memory and cognition [48]. A recent phase 2 trial failed to establish a drug-placebo difference. A similar agent -.- ABT-384 -.was terminated for futility when it failed to produce cognitive benefit [49]. Endogenous glucocorticoids have a wide spectrum of physiological effects and are elevated in $\mathrm{AD}$ where they have been correlated with dysregulation of the hypothalamic-pituitary-adrenocortical axis, hippocampal degeneration, and reduced cognitive function. Non-clinical studies show that increased glucocorticoids levels accelerate the formation of $\mathrm{A} \beta$ in animal models of $\mathrm{AD}$, promoting the amyloidogenic pathway and reducing $A \beta$ clearance [48]. These clinical and nonclinical observations support glucocorticoid reduction as a treatment target in $\mathrm{AD}$.

\section{Cognitive enhancing drugs with novel mechanisms of action in non-clinical development}

Beyond the mechanisms noted above and addressed in late stage trials, a number of other mechanisms are being considered to achieve cognitive enhancement in $\mathrm{AD}$. Among the targets currently addressed by agents under study are drug-induced effects on metabotropic glutamate receptor 5, cyclic adenosine monophosphate, norepinephrine, glucagon-like peptide 1, polyphenols, flavonoids, D1 and D2 dopamine receptors, and calcium channel modulation [50-55]. Some agents such as calcium channel blockers and oligomannate (described above) may have both cognitive enhancing and diseasemodifying properties.

\section{Comparison of drug development for cognitive enhancing and disease-modifying treatments for Alzheimer's disease}

There are substantial challenges in the development of both DMTs and cognitive enhancing agents. Table 2 presents the comparative advantages and challenges to be considered for each type of development program. Symptomatic therapies have an established regulatory pathway, known trial methodology with widely accepted outcome measures (primary and secondary), targets that are relatively well understood (ion channels and transmitter receptors), trials that demonstrate improvement above baseline and require relatively smaller sample sizes and shorter durations of exposure to observe drugplacebo differences, can be administered conveniently as oral medications, and usually cost less to develop. DMTs must establish a regulatory pathway and identify a

Table 1 Phosphodiesterase inhibitors assessed in clinical trials (2016-2020) [5, 25-28] (Year refers to the years in which the agent is listed on clinicaltrials.gov as being in a clinical trial)

\begin{tabular}{lllll}
\hline Year & Agent & PDE Target & Phase & Outcome \\
\hline 2020,2019 & BPN14770 & 4 & 2 & Synaptic, neuroprotection, anti-inflammatory \\
$2020,2019,2018,2017,2016$ & Cilostazol & 3 & 2 & Synaptic plasticity and neuroprotection; improved circulation \\
2019 & AR1001 & 5 & 2 & Synaptic plasticity and amyloid reduction \\
2017,2016 & Bl 409306 & 9 A & 3 & Cognitive enhancer \\
\hline
\end{tabular}


Table 2 Development of symptomatic cognitive enhancing drugs compared to development of disease-modifying agents

\begin{tabular}{|c|c|c|}
\hline Development & $\begin{array}{l}\text { Symptomatic Cognitive } \\
\text { Enhancing Agent }\end{array}$ & $\begin{array}{l}\text { Disease-Modifying } \\
\text { Agent }\end{array}$ \\
\hline Approved agents & Yes & No \\
\hline Defined regulatory pathway & Yes & No \\
\hline Validated target & Yes & No \\
\hline Conventional target & $\begin{array}{l}\text { Yes; receptors and ion } \\
\text { channels }\end{array}$ & $\begin{array}{l}\text { Some conventional targets such as enzymes and some } \\
\text { unconventional targets such as protein-protein interactions }\end{array}$ \\
\hline Clinical outcomes validated in successful trials & Yes & No \\
\hline Trial sample size & 200-400 per arm & $600-1200$ per arm \\
\hline Trial duration & $3-6$ months & 12-24 months \\
\hline Administration & Oral; patch & Oral; intravenous; subcutaneous; intramuscular \\
\hline Patient convenience & $\begin{array}{l}\text { More convenient; usually } \\
\text { orally administered }\end{array}$ & $\begin{array}{l}\text { Less convenient if intravenous, subcutaneous, or intramuscular } \\
\text { administration required }\end{array}$ \\
\hline Diagnosis & Usually phenotype-based & Phenotype-based usually with biomarker confirmation \\
\hline Target engagement biomarker & May not be included & Yes \\
\hline Disease-modification biomarker & No & Yes \\
\hline Preclinical application & No; symptoms required & Yes; trials can be biomarker based \\
\hline Prodromal application & Yes; none approved & Yes; none approved \\
\hline Alzheimer dementia application & Yes; approved & Yes, none approved \\
\hline Increasing drug-placebo difference over time & $\begin{array}{l}\text { No; cumulative benefit } \\
\text { not anticipated }\end{array}$ & Yes; cumulative benefit anticipated \\
\hline $\begin{array}{l}\text { Delayed start or randomized withdrawal trial } \\
\text { design show enduring effect of treatment }\end{array}$ & No & Yes \\
\hline Cost of development program & Lower & Higher \\
\hline Cost of treatment to patients & Lower & Higher \\
\hline Patient message & $\begin{array}{l}\text { Improved ability above } \\
\text { baseline function }\end{array}$ & $\begin{array}{l}\text { No improvement; less decline over time; delayed onset of dementia } \\
\text { (in predementia populations) }\end{array}$ \\
\hline
\end{tabular}

validated target, require larger and longer trials, are more costly to develop, are expected to be less convenient (intravenous or subcutaneous administration in many cases such as monoclonal antibodies), and will be more costly for patients and healthcare systems. Unique features of DMT development include possible extension to asymptomatic preclinical populations; use of biomarkers to select patients, show target engagement, and support disease-modification; and expectation of cumulative benefit and increasing drug-placebo difference with continued adherence to the medication regimen. Both types of therapy are needed to improve outcomes in individuals with $\mathrm{AD}$ continuum disorders, and it is highly likely that DMT and symptomatic therapies will be administered simultaneously to optimize patient benefit. Most current trials allow participants to be on the standard of care with ChE-Is with or without mementine; participants are randomized to drug or placebo on the background of approved therapy. This is one paradigm for combination therapy when an approved agent is allowed in a trial for a test agent. Sponsors and developers need to anticipate these challenges when considering development programs for DMTs or symptomatic therapies.

The contrast of symptomatic cognitive enhancing therapies and DMTs artificially simplifies these categories. There is evidence that combination therapy with cholinesterase inhibitors and memantine slows the progression of $\mathrm{AD}$ and may have a disease modifying effect [56]. Some cholinesterase inhibitors and M1 muscarinic agonists reduce amyloid precursor protein (APP) processing and lower amyloid plaque and neurofibrillary tangles in cell and animal models, respectively [57, 58]. Agents considered DMTs may have symptomatic effects through rescue of dysfunctional but not moribund cell populations by reducing local toxicity and enhancing neuroprotection $[59,60]$. Thus, DMTs can plausibly produce cognitive enhancement, and symptomatic therapies may have mechanistic properties that produce disease modification. In addition, DMTs may exhibit psychotropic properties by suppressing emergence of new behavioral symptoms if they effectively reduce the rate of progression of $\mathrm{AD}$ [61]. The conventional terminology derives from the developmental intent to interrupt cell 
death in the case of DMTs or to enhance cognition or reduce behavioral alterations with the symptomatic agents.

\section{Treatment of neuropsychiatric symptoms of Alzheimer's disease \\ Overview of recent trials for neuropsychiatric symptoms of Alzheimer's disease}

There are currently no approved treatments for any neuropsychiatric symptom in $\mathrm{AD}$; there is progress in clinical trials and trial methodology, several drugs are in late stage trials for behavioral disorders in $\mathrm{AD}$ or dementia, and one agent has been submitted to the FDA for approval as treatment for dementia-related psychosis (discussed below). Most of the agents in trials are re-positioned from successful development programs for behavioral changes in patients with major mental disorders (e.g., schizophrenia, bipolar illness, major depressive disorder, insomnia). Figure 2 shows the number of drugs in clinical trials for the years 2016-2020 that addressed behavioral symptoms as the primary outcome of the trials $[5,25-28]$. The number of agents is relatively small; $4-8$ in Phase 3 and 2-7 in Phase 2 , over the 5 year period. The trials have been facilitated by development of consensus syndrome definitions useful in clinical trials including agitation in cognitive impairment [62], psychosis in major and mild neurocognitive disorders [63], and apathy in dementia [64].

The neurobiological bases of behavioral changes in $\mathrm{AD}$ are not precisely known. Behavior is an emergent property of integrated circuits with distributed anatomies and reliance on multiple transmitters. Distinct circuits comprising unique anatomies and neurotransmitters underly different behavioral phenotypes [65]. In $\mathrm{AD}$, the presence of a variety of types of neurotoxic protein assemblies (amyloid, tau, alpha-synuclein, transactive response DNA binding protein-43 [TDP-43]) induce synaptic dysfunction and network/circuit dysfunction [66]. Circuit abnormalities give rise to behavioral syndromes with neurobiologic, genetic, and resilience factors all contributing to the final behavioral phenotype exhibited by the patient. Measures such as FDG metabolism reflect synaptic dysfunction and demonstrate distinct behaviorrelated circuit patterns including right frontotemporal hypometabolism in patients with agitation [67]; bilateral anterior cingulate and orbitofrontal hypometabolism in patients with apathy [68]; or decreased orbitofrontal metabolism in AD patients with psychosis [69]. Exploration of specific pathologic and biochemical correlates of behavioral changes in $\mathrm{AD}$ has been hampered by the long period between when the patients come to autopsy and the time the behavioral symptoms are manifest [70].

\section{Agitation}

Development of new therapies for agitation is currently the most active area of drug development for neuropsychiatric symptoms in AD. There are 8 agents in clinicals trials for agitation. Brexpiprazole (Rexulti ${ }^{\mathrm{T}}$ ) is approved for treatment of schizophrenia and as adjunctive therapy for major depressive disorder. Preliminary trials in $\mathrm{AD}$ demonstrated a drug-placebo difference in agitation reduction with the $2 \mathrm{mg}$ daily dose, not the 1 $\mathrm{mg}$ dose [71]. A confirmatory trial is in progress. Dextromethorphan/quinidine (DM/Q. Nuedexta $\left.{ }^{\mathrm{Tm}}\right)$ was shown to reduce agitation in a Phase 2 trial [72]. Phase 3 trials of the deuterated version of DM/Q failed to confirm the anti-agitation effect, and additional trials are on-going. AX-05, a combination of dextromethorphan and bupropion, had a successful Phase 2 trial with a significant drug-placebo difference in agitation reduction. Phase 3 trials are planned. Nobilone, a cannabinoid agent, was shown to reduce agitation in $\mathrm{AD}$ in a doubleblind crossover study [73]. Sedation was more common in the nobilone-treated patients compared to those receiving placebo. Prazosin, a postsynaptic alpha-1

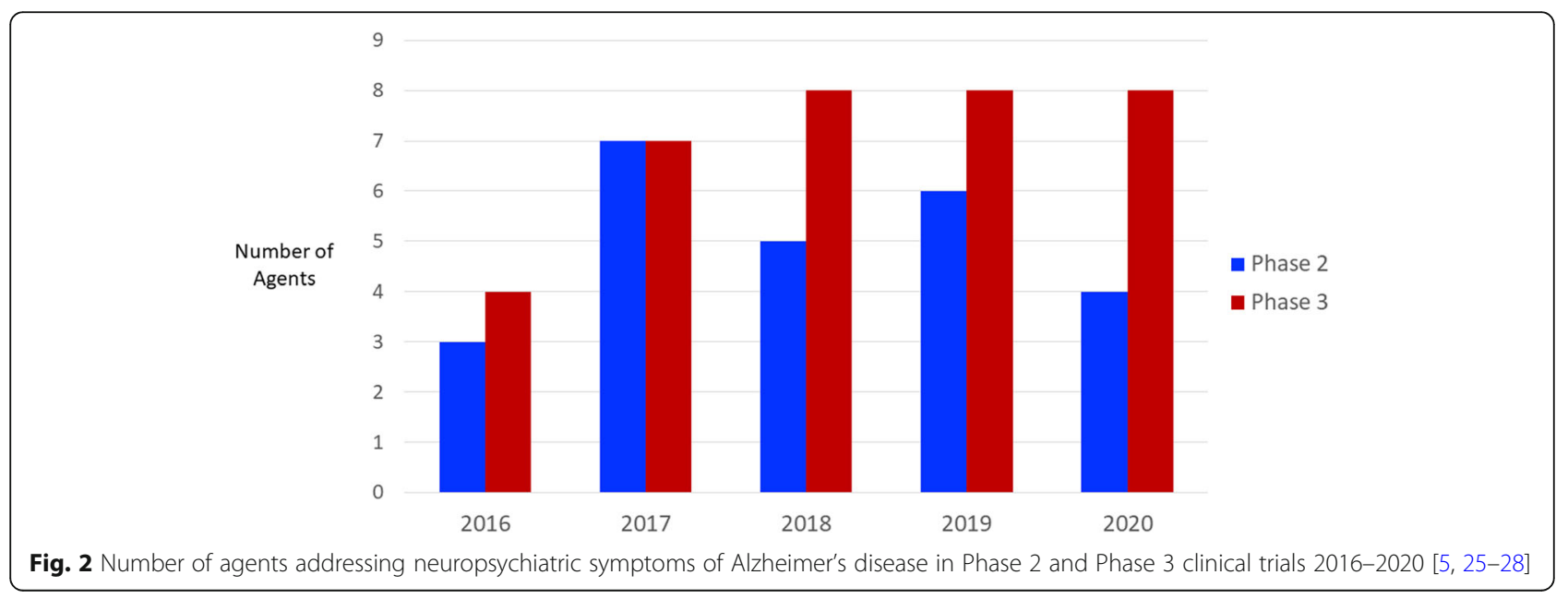


adrenergic receptor antagonist has shown preliminary anti-agitation effects and is being further assessed [74].

\section{Psychosis}

There are no approved treatments for psychosis in any form of dementia. Pimavanserin $\left(\right.$ Nuplazid $\left.^{\mathrm{TM}}\right)$ is approved for psychosis in Parkinson' disease (PD) without dementia [75]. Pimavanserin was shown to be effective in a Phase 2 trial of AD with psychosis [76]. These development milestones led to the HARMONY trial of dementia-related psychosis [77]. This was a randomized discontinuation trial that includes participants with five types of dementia - AD, Parkinson' disease dementia, dementia with Lewy bodies, frontotemporal lobar degeneration, and vascular dementia. The trial met its primary outcome of earlier relapse in the placebo group compared to the active therapy group, and pimavanserin has been submitted for possible marketing approval by the FDA.

Psychosis is associated with more rapid cognitive and functional decline in $\operatorname{AD}[78,79]$. Future studies will determine if successful treatment of psychosis will ameliorate the rate of cognitive and functional loss.

\section{Apathy}

Apathy is among the most common manifestations of $\mathrm{AD}$ and other dementias [80]. No treatment has been approved by the FDA for treatment of this neuropsychiatric syndrome. Methylphenidate (Ritalin ${ }^{\mathrm{sm}}$ ) was assessed in a Phase 2 trial and demonstrated improvement on the Clinical Global Impression of Improvement (CGI-I) and the apathy subscale of the Neuropsychiatric Inventory (NPI) [81]; the drug-placebo difference on the Apathy Evaluation Scale (the primary outcome of the trial) was not significant [82]. A follow-up study is in progress [83]. A clinical trial of modafinil in apathy did not establish a drug placebo difference [84].

PET and fMRI studies of apathy in neurodegenerative disorders show abnormalities in frontal regions associated with impairments in planning and decision making and in the anterior cingulate cortices related to emotional blunting and loss of motivation [85].

\section{Sleep}

Sleep disorders are common in AD and affect the lives of the patient and the caregiver [86, 87]. Poor sleep adversely impacts cognition and behavior. In addition, there is increasing evidence that sleep deprivation increases the concentration of soluble amyloid in the brain and results in accumulation of insoluble amyloid; sleep extension has the opposite effect [88]. Sleep deprivation also increases levels of the tau protein in human CSF and accelerates the spread of tau aggregates in neural networks [89].
Suvorexant, a dual orexin antagonist (DORA), was recently shown in a double blind, placebo-controlled phase 3 trial to reduce insomnia in AD. Total sleep time was significantly increased and wakefulness after sleep onset (WASO) was significantly decreased [90]. Suvorexant had a prior approval for insomnia and successful treatment of insomnia in AD did not result in specific labeling for insomnia in AD. However, clinical and adverse event information is now included in the Package Insert to guide practitioner use of suvorexant in AD. This highlights the challenge of pseudospecificity in labeling for AD behavioral indications when the agent tested for treatment of AD has been approved for a similar indication in a non-AD disorder [24].

Lemborexant, a DORA, is being investigated for irregular sleep wake rhythm disorder (ISWRD) in AD [91]. ISWRD is a circadian rhythm disorder characteristic of AD, other NDD, and some developmental disorders. ISWRD is thought to be produced by degeneration of neurons of the suprachiasmatic nucleus $(\mathrm{SCN})$ of the hypothalamus, decreased responsiveness of the circadian "clock" to entraining agents such as light and activity, and decreased exposure to bright light and structured social and physical activity during the day common in cognitively compromised individuals. Treatment of ISWRD seeks to restore a more normal circadian rhythm by consolidating sleep during the night and wakefulness during the day [92]. Restoration of daily circadian rhythms is a novel approach to $\mathrm{AD}$ therapy that may have sleep, wakefulness, cognitive, and behavior effects. With appropriate biomarkers and trial designs, such interventions could be demonstrated to be DMTs given the growing evidence of the relationship between sleep disorders and exacerbation of AD pathology [88, 93].

Additional agents currently under study for sleep disorders in $\mathrm{AD}$ include zopiclone and zolpidem [5].

\section{Challenges for clinical trial of agents for treatment of neuropsychiatric syndromes}

A major challenge for clinical trials of treatments for neuropsychiatric syndromes is the occurrence of robust placebo-group improvement. This reduction in symptoms in the no-active-treatment group may be a true placebo response in the participant, a placebo response in the caregiver who reports the response in most clinical trials, regression to the mean of elevated scale scores at the time of screening for the trial, natural history of agitation, and behavioral improvement in response to the clinical trial circumstances including increased family involvement, greater staff attention in residential settings, and interaction with research staff [94].

The substantial placebo response in behavioral trials is the greatest challenge to being able to demonstrate a 
treatment effect of the active agent. A variety of strategies have been implemented in an attempt to understand and manage the placebo-group effects in trials of neuropsychiatric agents (Table 3). Placebo run-in periods are used in randomized clinical trials to exclude patients after screening, but before randomization. In theory, run-in periods increase the probability of detecting a potential treatment effect, although they may reduce both external and internal validity [95]. Placebo run-in periods help identify patients who respond to the placebo in the early period of therapy, and these can be excluded from the trial if they no longer meet entry criteria. Run-in periods help to examine participant adherence, and those unlikely to comply with study procedures and whose inclusion would reduce study power can be excluded at the time of randomization [96]. A variant of the placebo run-in was used in the pimavanserin trial for Parkinson's disease psychosis [75]. Patients received 2 weeks of psychosocial therapy prior to randomization and those responding and no longer meeting criteria for study entry were excluded. Fiftythree patients $(40 \%$ of excluded patients, $17 \%$ of screened patients) did not meet study entry criteria at the time of randomization although they had appropriate scores at the time of screening. If no placebo run-in is conducted, there is still a period between screening and randomization that may affect participant scores. Participants should meet study criteria at screening and at randomization to limit the effects of regression to the mean or early response to study participation [97]. Patients with more severe symptoms tend to have more evident responses to therapy, and substantial sustained psychopathology should be required for entry [76]. Across trials it is observed that those with 2 arms and a 1:1 randomization to drug or placebo have smaller placebo responses (and larger drug-placebo differences) than multi-arm trials [98]. Central review of the collection of the primary outcomes measures and the entry criteria (at randomization) helps ensure that the behavioral changes are accurately rated and sufficiently severe to meet the randomization criteria [99]. Central reviewers listen to a recorded audio tape of the interview or may watch a videotaped interview. Competent central reviewers must be identified for each language in which the interviews are conducted. The sequential parallel comparison design (SPCD) was created specifically to provide insight into the placebo response. The SPCD has 2 stages: stage 1 is a typical placebo-controlled design; stage 2 entails the re-randomization of placebo nonresponders (patients in the placebo arm of stage 1 who did not improve) to drug or placebo [100]. This design in used in depression and pain trials; the dextromethorphan/quinidine trial of agitation in $\mathrm{AD}$ is the only example of its application in AD [72]. In this trial, there was a drug-placebo separation in both stage 1 and stage 2. The randomized discontinuation design is another strategy for limiting placebo responses. All patients are treated in the first period of the trial with the active therapy. Responders to therapy are then randomly assigned to drug or placebo; the primary outcome is the rate of symptom relapse or time to symptom relapse in the placebo arm compared to the active therapy arm. The design selects for those most likely to respond and minimizes placebo responses. Randomized

Table 3 Design adjustments used to manage and understand placebo effects in trials for neuropsychiatric symptoms and syndromes

\begin{tabular}{|c|c|}
\hline Design Adjustment & Purpose \\
\hline Placebo lead-in & $\begin{array}{l}\text { Exclude patients who no longer meet trial entry criteria after } 2 \text { weeks of placebo treatment } \\
\text { Identify non-adherent patients whose participation in the trial would reduce power to ob- } \\
\text { serve a drug-placebo difference }\end{array}$ \\
\hline Pre-randomization psychosocial intervention & $\begin{array}{l}\text { Exclude patients who no longer meet trial entry criteria after } 1-2 \text { weeks of psychosocial } \\
\text { treatment }\end{array}$ \\
\hline $\begin{array}{l}\text { Participants meet entry criteria at screening and } \\
\text { baseline }\end{array}$ & Reduce chance of score improvement by regression to the mean \\
\hline $\begin{array}{l}\text { Central review of scales whose scores determine entry } \\
\text { to the trial }\end{array}$ & More reliable review of the data with fewer site influences \\
\hline $\begin{array}{l}\text { Patients have at least moderately severe symptoms at } \\
\text { screening and randomization }\end{array}$ & More severe symptoms are less likely to respond to placebo \\
\hline Longer trials of 12 to 24 weeks & Placebo responses are often greatest at study onset and become gradually less marked \\
\hline Two-arm design with 1:1 randomization & Placebo responses are higher in trials with several active treatment arms \\
\hline Sequential parallel comparison design (SPCD) & $\begin{array}{l}\text { 2nd stage of the SPCD has only placebo non-responders in the placebo (and active) arm of } \\
\text { the trials }\end{array}$ \\
\hline Randomized discontinuation design & $\begin{array}{l}\text { All participants are on active treatment in the first period of the trial; only responders to } \\
\text { active therapy are randomized to drug or placebo }\end{array}$ \\
\hline
\end{tabular}


discontinuation trials have demonstrated the efficacy of haloperidol, risperidone, and pimavanserin for behavioral disturbances in $\mathrm{AD}[77,101,102]$.

\section{Drugs for treatment of neuropsychiatric symptoms with novel mechanisms of action in non-clinical development} Most drugs directed at behavioral symptoms in AD are assessed first in primary psychiatric disorders such as schizophrenia, bipolar illness, depression, or sleep disorders. The absence of a known symptom-specific biology for the neuropsychiatric syndromes of AD makes it difficult to target these behaviors with agents unique to $\mathrm{AD}$. There are few neuropsychiatric agents in Phase 1 AD development programs because the early evaluation of the agents is conducted in psychiatric programs. The diversification of targets for schizophrenia suggests that agents with more varied mechanisms of action will eventually be directed to behavioral symptoms of AD. Glutamatergic agents (metabotropic 1,2, and 3 receptor agonists), serotonin agents $\left(5-\mathrm{HT}_{1 \mathrm{~A}}\right.$ agonists, $5-\mathrm{HT}_{2 \mathrm{C}}$ antagonists and agonists, $5-\mathrm{HT}_{3}$ antagonists, $5-\mathrm{HT}_{6}$ antagonists, and $5-\mathrm{HT}_{7}$ antagonists), gamma-aminobutyric acid (GABA) allosteric modulators, neuropeptide agents (neurokinin-3, neurotensin), cannabinoids, antiinflammatory agents (producing cytokine reduction), and targeting of trace amine-associated receptor 1 (TAAR1) and $5-\mathrm{HT}_{1 \mathrm{~A}}$ are being assessed in nonclinical models of schizophrenia or in early human trials and, if successful, will likely be evaluated for their ability to ameliorate psychosis or agitation in $\mathrm{AD}[103,104]$.

There are no drugs currently in clinical trials for treatment of depression in $\mathrm{AD}$ despite a high prevalence of depressive mood changes in the disorder [105]. Conventional antidepressants approved for treatment of major depression have largely failed in clinical trials for depression of AD [106]. Antidepressants with novel mechanisms being assessed for depression in major depression and bipolar disorder can be expected to be evaluated for treatment of depression in AD. Approaches being assessed for depression include targeting inflammatory cytokines (TNF- $\alpha$, IL-1B, IL-6), oxidative and nitrosative stress, PPAR $\gamma$, glucagon-like peptide 1, mitochondrial modulation and bioenergetics, glutamatergic pathways, $\mathrm{S}$-adenosyl-methionine, neurotrophin signaling, PDE $10 \mathrm{~A}$, receptors of psychedelic agents, and the opioid system [107-111].

\section{Discussion}

There is a high rate of negative outcomes in clinical trials for drugs being developed to improve cognitive and behavioral symptoms of AD [6]. Most trials for symptomatic agents do not confirm the diagnosis of $\mathrm{AD}$ with biomarkers and use the $\mathrm{AD}$ amnestic phenotype for trial inclusion. In the PRIME trial of aducanumab it was shown that $39 \%$ of patients with the mild AD dementia phenotype did not have brain amyloid when assessed with amyloid PET [112]. This suggests that a substantial number of participants in trials for symptomatic agents do not have the underlying biology of $\mathrm{AD}$. These agents are not amyloid-focused or amyloid-dependent but including patients with non-AD disorders makes it more difficult to extrapolate results from $\mathrm{AD}$ animal models to human trials, may reduce the power of the trial to demonstrate a drug-placebo difference, may result in slower progression in the placebo group, and impedes the developer's ability to understand the relationship of the intervention to the underlying biology. The evolution of blood tests that accurately predict brain amyloidosis and other $\mathrm{AD}$ pathology may greatly improve the feasibility of creating more homogeneous trial populations for assessment of symptomatic agents [113-115].

Precision drug development depends on demonstrating a pharmacodynamic effect of the agent that predicts the expected cognitive or behavioral impact [116]. A variety of such pharmacodynamic biomarkers are evolving for use in trials of DMTs; few have been developed for symptomatic agents. CSF cGMP is increased in trials of PDE inhibitors and provides a useful pharmacodynamic readout [117]. FDG PET is a measure of synaptic function, and the hypometabolism observed in $\mathrm{AD}$ is partially reversed by symptomatic agents such as ChE-Is that affect synaptic function [118]. FDG PET showed less reduction of metabolism in response to the monoamine oxidase inhibitor rasagiline compared to placebo supporting a pharmacodynamic effect of this agent [43]. Similarly, cerebral blood flow is increased by symptomatic agents as measured by PET [119]. fMRI demonstrates changes in connectivity following cholinergic therapy [120] and may be useful in assessing other classes of symptomatic agents. More pharmacodynamic measures are needed to inform development of symptomatic agents and to improve the translational gap that exits between nonclinical observations and human responses.

Sensitive clinical outcomes are needed to demonstrate drug-placebo differences, and new tools that promise to perform well in trials are being introduced. The Neuropsychological Test Battery (NTB) may be more sensitive than the ADAS-cog in mild AD and more likely to show a drug-placebo difference in this population where progression is modest in the course of a short trial [121]. Computerized assessments have advantages in standardized administration, reduction of missing data, collection of variables such as reaction time not available from paper-and-pencil tests, and automated interface with electronic databases of trial sponsors [122]. These assessments may be particularly useful in Phase 2 trials with smaller sample sizes and an experimental medicine approach. Matching the cognitive signature of an agent's 
mechanism of action to the target pathology or transmitter change may improve trial outcomes. A trial of rotigotine --- a dopaminergic agent influencing frontalsubcortical circuits --- had no effect on the ADAS-cog but showed a significant improvement on the Frontal Assessment Battery (FAB) [42]. The FAB assesses executive/frontal function; the ADAS-cog lacks executive/ frontal measures. The Amsterdam-Instrumental Activities of Daily Living Scale [123] may better characterize ADLs of contemporary life and allow more reliable differentiation between drug and placebo than previous instruments. Cognitive-functional composites may be more sensitive, reliable, and more accurate in reflecting patient status and capturing longitudinal change critical to successful trials $[124,125]$. Composites are being explored in trials of patients with mild cognitive impairment and early AD dementia.

This review is limited by its dependence on clinicaltrials.gov as the source of information on agents currently in trials. While this registry is comprehensive, it under-represents agents in Phase 1 and some cognitive enhancers or psychotropic agents in early development may have escaped detection. There is no similar registry for agents for behavioral and cognitive symptoms of $\mathrm{AD}$ in the nonclinical phases of development, and the catalogue of agents in this stage is no doubt flawed. The principles of drug development applicable across development programs are emphasized.

\section{Conclusions}

There has been progress in developing new therapies for behavioral aspects of AD. Suvorexant has been shown to improve insomnia in $\mathrm{AD}$, and pimavanserin has been submitted to the FDA for dementia-related psychosis including psychosis in AD. Trials of agitation and apathy have promising preliminary results. New criteria for specific behavioral syndromes (agitation, psychosis, apathy) in $\mathrm{AD}$ assist in reducing heterogeneity of trial populations, presenting agents to the FDA, and educating prescribers on how best to use emerging treatments. Trial designs and means of managing the placebo response in trials of behavioral disorders have advanced. Less progress is currently evident in the development of cognitive enhancing agents but better trial participant characterization, use of pharmacodynamic biomarkers, and implementation of more sensitive outcomes may assist in improving the success of development programs. Continued improvements will result in progress toward developing cognitive enhancing and psychotropic agents to address the unmet needs of patients with AD.

\section{Abbreviations}

Aß: Amyloid beta; AD: Alzheimer's disease; ADAS: Alzheimer's Disease Assessment Scale; ADAS-cog: Alzheimer's Disease Assessment Scale cognitive subscale; ADL: Activities of daily living; cAMP: Cyclic adenosine monophosphate; CGIC: Clinical Global Impression of Change; CGI-I: Clinical Global Impression of Improvement; CGMP: Cyclic guanosine

monophosphate; ChE-Is: Cholinesterase inhibitors; CIBIC+: Clinical Interview Based Impression of Change with caregiver input; CSF: Cerebrospinal fluid; DM/Q: Dextramethorphan/quinidine (Nuedexta $\left.{ }^{T M}\right) ; D M T$ : Disease-modifying therapy; DORA: Dual orexin antagonist; FAB: Frontal Assessment Battery; FDA: U.S. Food and Drug Administration; FDG: Fluorodeoxyglucose; fMRI: Functional magnetic resonance imaging; GABA: Gamma-aminobutyric acid; GV-971: Oligomannate ${ }^{\text {TM; }}$ HSD: Hydroxysteroid dehydrogenase; ISWR

D: Irregular sleep wake rhythm disorder; MMSE: Mini-Mental State Examination; NDD: Neurodegenerative disorder; NMDA: N-methyl-Daspartate; NMPA: National Medical Products Administration; NPI: Neuropsychiatric Inventory; NTB: Neuropsychological Test Battery; PD: Parkinson's disease; PDE: Phosphodiesterase; PDE-Is: Phosphodiesterase inhibitors; PET: Positron emission tomography; SPCD: Sequential parallel comparison design; TAAR1: Trace amine-associated receptor 1;

WASO: Wakefulness after sleep onset

Acknowledgements

Not applicable.

Author's contributions

$J C$ is responsible for all aspects of this manuscript. The author read and approved the final manuscript.

\section{Funding}

JC is supported by Keep Memory Alive (KMA); NIGMS grant P20GM109025; NINDS grant U01NS093334; and NIA grant R01AG053798.

Availability of data and materials

Not applicable.

Ethics approval and consent to participate

Not applicable.

Consent for publication

Not applicable.

Competing interests

JC has provided consultation to Acadia, Actinogen, AgeneBio, Alkahest, Alzheon, Annovis, Avanir, Axsome, Biogen, Cassava, Cerecin, Cerevel, Cortexyme, Cytox, EIP Pharma, Eisai, Foresight, GemVax, Genentech, Green Valley, Grifols, Karuna, Merck, Novo Nordisk, Otsuka, Resverlogix, Roche, Samumed, Samus, Signant Health, Suven, and United Neuroscience pharmaceutical and assessment companies. Dr. Cummings has stock options in ADAMAS, AnnovisBio, MedAvante, BiOasis. Dr. Cummings owns the copyright of the Neuropsychiatric Inventory.

Received: 26 August 2020 Accepted: 2 January 2021

Published online: 13 January 2021

\section{References}

1. Masters CL, Bateman R, Blennow K, Rowe CC, Sperling RA, Cummings JL. Alzheimer's disease. Nat Rev Dis Primers. 2015;1:150.

2. Scheltens P, Blennow K, Breteler MM, de Strooper B, Frisoni GB, Salloway S, et al. Alzheimer's disease. Lancet. 2016:388(10043):505-17.

3. Francis PT, Ramirez MJ, Lai MK. Neurochemical basis for symptomatic treatment of Alzheimer's disease. Neuropharmacology. 2010;59(4-5):221-9.

4. Atri A. The Alzheimer's disease clinical spectrum: diagnosis and management. Med Clin North Am. 2019;103(2):263-93.

5. Cummings J, Lee G, Ritter A, Sabbagh M, Zhong K. Alzheimer's disease drug development pipeline: 2020. Alzheimer Dement TRCI. 2020;20(6):e12050.

6. Cummings $\mathrm{J}$, Morstorf T, Zhong K. Alzheimer's disease drug-development pipeline: few candidates, frequent failures. Alzheimers Res Ther. 2014;6(4):37.

7. Rogers SL, Doody RS, Mohs RC, Friedhoff LT. Donepezil improves cognition and global function in Alzheimer disease: a 15-week, double-blind, placebocontrolled study. Donepezil Study Group. Arch Intern Med. 1998;158(9): 1021-31.

8. Tan CC, Yu JT, Wang HF, Tan MS, Meng XF, Wang C, et al. Efficacy and safety of donepezil, galantamine, rivastigmine, and memantine for the 
treatment of Alzheimer's disease: a systematic review and meta-analysis. J Alzheimers Dis. 2014;41(2):615-31.

9. Dou KX, Tan MS, Tan CC, Cao XP, Hou XH, Guo QH, et al. Comparative safety and effectiveness of cholinesterase inhibitors and memantine for Alzheimer's disease: a network meta-analysis of 41 randomized controlled trials. Alzheimers Res Ther. 2018;10(1):126.

10. Winblad B, Engedal K, Soininen H, Verhey F, Waldemar G, Wimo A, et al. A 1-year, randomized, placebo-controlled study of donepezil in patients with mild to moderate AD. Neurology. 2001;57(3):489-95.

11. Rodda J, Morgan S, Walker Z. Are cholinesterase inhibitors effective in the management of the behavioral and psychological symptoms of dementia in Alzheimer's disease? A systematic review of randomized, placebocontrolled trials of donepezil, rivastigmine and galantamine. Int Psychogeriatr. 2009;21(5):813-24.

12. Cummings JL, Schneider L, Tariot PN, Kershaw PR, Yuan W. Reduction of behavioral disturbances and caregiver distress by galantamine in patients with Alzheimer's disease. Am J Psychiatry. 2004;161(3):532-8.

13. Whitehouse PJ, Price DL, Struble RG, Clark AW, Coyle JT, Delon MR. Alzheimer's disease and senile dementia: loss of neurons in the basal forebrain. Science. 1982;215(4537):1237-9.

14. Hampel H, Mesulam MM, Cuello AC, Farlow MR, Giacobini E, Grossberg GT, et al. The cholinergic system in the pathophysiology and treatment of Alzheimer's disease. Brain. 2018;141(7):1917-33.

15. Mesulam MM. Cholinergic circuitry of the human nucleus basalis and its fate in Alzheimer's disease. J Comp Neurol. 2013;521(18):4124-44.

16. Guo H, Grajauskas L, Habash B, D'Arcy RC, Song X. Functional MRI technologies in the study of medication treatment effect on Alzheimer's disease. Aging Med (Milton). 2018;1(1):75-95.

17. Mega MS, Dinov ID, Porter V, Chow G, Reback E, Davoodi P, et al. Metabolic patterns associated with the clinical response to galantamine therapy: a fludeoxyglucose $f 18$ positron emission tomographic study. Arch Neurol. 2005;62(5):721-8.

18. Holiga S, Abdulkadir A, Kloppel S, Dukart J. Functional magnetic resonance imaging in Alzheimer' disease drug development. Methods Mol Biol. 2018; 1750:159-63.

19. Davis KL, Thal LJ, Gamzu ER, Davis CS, Woolson RF, Gracon SI, et al. A double-blind, placebo-controlled multicenter study of tacrine for Alzheimer's disease. The Tacrine collaborative study group. N Engl J Med. 1992;327(18):1253-9.

20. Farlow M, Gracon SI, Hershey LA, Lewis KW, Sadowsky CH, Dolan-Ureno J. A controlled trial of tacrine in Alzheimer's disease. The Tacrine Study Group. JAMA. 1992;268(18):2523-9.

21. Folstein MF, Folstein SE, McHugh PR. "mini-mental state". A practical method for grading the cognitive state of patients for the clinician. J Psychiatr Res. 1975;12(3):189-98.

22. Guy W. Clinical Global Impressions. ECDEU Assessment Manual for Psychopharmacology—Revised. . Rockville, MD: U.S. Department of Health, Education, and Welfare; Public Health Service, Alcohol; Drug Abuse, and Mental Health Administration; National Institute of Mental Health; Psychopharmacology Research Branch; Division of Extramural Research Programs; 1976

23. Rosen WG, Mohs RC, Davis KL. A new rating scale for Alzheimer's disease. Am J Psychiatry. 1984;141(11):1356-64.

24. Leber P. Guidelines for the clinical evaluation of antidementia drugs. First draft. Technical Report. FDA Neuro-Pharm Group. 1990.

25. Cummings J, Morstorf T, Lee G. Alzheimer's drug-development pipeline: 2016. Alzheimers Dement (N Y). 2016;2(4):222-32.

26. Cummings J, Lee G, Mortsdorf T, Ritter A, Zhong K. Alzheimer's disease drug development pipeline: 2017. Alzheimers Dement (N Y). 2017:3(3):367-84

27. Cummings J, Lee G, Ritter A, Zhong K. Alzheimer's disease drug development pipeline: 2018. Alzheimers Dement (N Y). 2018;4:195-214.

28. Cummings J, Lee G, Ritter A, Sabbagh M, Zhong K. Alzheimer's disease drug development pipeline: 2019. Alzheimers Dement (N Y). 2019;5:272-93.

29. Wang $X$, Sun G, Feng T, Zhang J, Huang X, Wang T, et al. Sodium oligomannate therapeutically remodels gut microbiota and suppresses gut bacterial amino acids-shaped neuroinflammation to inhibit Alzheimer's disease progression. Cell Res. 2019;29(10):787-803.

30. Heneka MT, Carson MJ, El Khoury J, Landreth GE, Brosseron F, Feinstein DL, et al. Neuroinflammation in Alzheimer's disease. Lancet Neurol. 2015;14(4):388-405.

31. Sochocka M, Donskow-Lysoniewska K, Diniz BS, Kurpas D, Brzozowska E, Leszek J. The gut microbiome alterations and inflammation-driven pathogenesis of Alzheimer's disease-a critical review. Mol Neurobiol. 2019; 56(3):1841-51.

32. Atri A, Frolich L, Ballard C, Tariot PN, Molinuevo JL, Boneva N, et al. Effect of idalopirdine as adjunct to cholinesterase inhibitors on change in cognition in patients with Alzheimer disease: three randomized clinical trials. JAMA. 2018;319(2):130-42.

33. Khoury R, Grysman N, Gold J, Patel K, Grossberg GT. The role of 5 HT6receptor antagonists in Alzheimer's disease: an update. Expert Opin Investig Drugs. 2018;27(6):523-33.

34. Verma S, Kumar A, Tripathi T, AK. Muscarinic and nicotinic acetylcholine receptor agonists: current scenario in Alzheimer's disease therapy. J Pharm Pharmacol. 2018;70(8):985-93.

35. Sabri O, Meyer PM, Graf S, Hesse S, Wilke S, Becker GA, et al. Cognitive correlates of alpha4beta2 nicotinic acetylcholine receptors in mild Alzheimer's dementia. Brain. 2018:141(6):1840-54.

36. Chase TN, Farlow MR, Clarence-Smith K. Donepezil plus solifenacin (CPC-201) treatment for Alzheimer's disease. Neurotherapeutics. 2017;14(2):405-16.

37. Voss T, Li J, Cummings J, Farlow M, Assaid C, Froman S, et al. Randomized, controlled, proof-of-concept trial of MK-7622 in Alzheimer's disease. Alzheimers Dement (N Y). 2018;4:173-81.

38. Avery EE, Baker LD, Asthana S. Potential role of muscarinic agonists in Alzheimer's disease. Drugs Aging. 1997;11(6):450-9.

39. Bodick NC, Offen WW, Levey Al, Cutler NR, Gauthier SG, Satlin A, et al. Effects of xanomeline, a selective muscarinic receptor agonist, on cognitive function and behavioral symptoms in Alzheimer disease. Arch Neurol. 1997; 54(4):465-73.

40. Phillips C, Fahimi A, Das D, Mojabi FS, Ponnusamy R, Salehi A. Noradrenergic system in Down syndrome and Alzheimer's disease a target for therapy. Curr Alzheimer Res. 2016;13(1):68-83.

41. D'Amelio M, Puglisi-Allegra S, Mercuri N. The role of dopaminergic midbrain in Alzheimer's disease: translating basic science into clinical practice. Pharmacol Res. 2018;130:414-9.

42. Koch G, Motta C, Bonni S, Pellicciari MC, Picazio S, Casula EP, et al. Effect of rotigotine vs placebo on cognitive functions among patients with mild to moderate Alzheimer disease: a randomized clinical trial. JAMA Netw Open. 2020;3(7):e2010372.

43. Ritter DMA, Thomas R, Andrews R, Lukic A, Revta C, et al., editors. The effects of rasagiline upon cerebral glucose metabolism, cognition, and tau in patients with mild to moderate Alzheimer's disease. San Diego: 12th Clinical Trials on Alzheimer's Disease Congress; 2019.

44. Schneider LS, Geffen Y, Rabinowitz J, Thomas RG, Schmidt R, Ropele S, et al. Low-dose ladostigil for mild cognitive impairment: a phase 2 placebocontrolled clinical trial. Neurology. 2019;93(15):e1474-e84

45. Nave S, Doody RS, Boada M, Grimmer T, Savola JM, Delmar P, et al. Sembragiline in moderate Alzheimer's disease: results of a randomized, double-blind, placebo-controlled phase II trial (MAyflOwer RoAD). J Alzheimers Dis. 2017:58(4):1217-28.

46. Heckman PR, Wouters C, Prickaerts J. Phosphodiesterase inhibitors as a target for cognition enhancement in aging and Alzheimer's disease: a translational overview. Curr Pharm Des. 2015;21(3):317-31.

47. Boland K, Moschetti V, Dansirikul C, Pichereau S, Gheyle L, Runge F, ZimdahlGelling H, Sand M. A phase I, randomized, proof-of-clinical-mechanism study assessing the pharmacokinetics and pharmacodynamics of the oral PDE9A inhibitor Bl 409306 in healthy male volunteers. Hum Psychopharmacol. 2017; 32(1). https://doi.org/10.1002/hup.2569. PMID: 28120486

48. Libro R, Bramanti P, Mazzon E. Endogenous glucocorticoids: role in the etiopathogenesis of Alzheimer's disease. Neuro Endocrinol Lett. 2017;38(1):1-12

49. Marek GJ, Katz DA, Meier A, Greco N, Zhang W, Liu W, et al. Efficacy and safety evaluation of HSD-1 inhibitor ABT-384 in Alzheimer's disease. Alzheimers Dement. 2014;10(5 Suppl):S364-73.

50. Dal-Pan A, Dudonne S, Bourassa P, Bourdoulous M, Tremblay C, Desjardins $Y$, et al. Cognitive-enhancing effects of a polyphenols-rich extract from fruits without changes in neuropathology in an animal model of Alzheimer's disease. J Alzheimers Dis. 2017:55(1):115-35.

51. Gu XH, Xu LJ, Liu ZQ, Wei B, Yang YJ, Xu GG, et al. The flavonoid baicalein rescues synaptic plasticity and memory deficits in a mouse model of Alzheimer's disease. Behav Brain Res. 2016;311:309-21.

52. Izumi H, Shinoda Y, Saito T, Saido TC, Sato K, Yabuki Y, et al. The diseasemodifying drug candidate, SAK3 improves cognitive impairment and inhibits amyloid beta deposition in app knock-in mice. Neuroscience. 2018; 377:87-97. 
53. Li T, Jiao JJ, Holscher C, Wu MN, Zhang J, Tong JQ, et al. A novel GLP-1/GIP/ Gcg triagonist reduces cognitive deficits and pathology in the 3xTg mouse model of Alzheimer's disease. Hippocampus. 2018;28(5):358-72.

54. Shineman DW, Carman AJ, Dacks PA, Lane RF, Fillit HM. Progress in novel cognitive enhancers for cognitive aging and Alzheimer's disease. Alzheimers Res Ther. 2013:5(5):45.

55. Svensson KA, Hao J, Bruns RF. Positive allosteric modulators of the dopamine D1 receptor: a new mechanism for the treatment of neuropsychiatric disorders. Adv Pharmacol. 2019;86:273-305.

56. Atri A, Hendrix SB, Pejovic V, Hofbauer RK, Edwards J, Molinuevo JL, et al. Cumulative, additive benefits of memantine-donepezil combination over component monotherapies in moderate to severe Alzheimer's dementia: a pooled area under the curve analysis. Alzheimers Res Ther. 2015;7(1):28.

57. Fisher A. M1 muscarinic agonists target major hallmarks of Alzheimer's disease--the pivotal role of brain M1 receptors. Neurodegener Dis. 2008;5(34):237-40.

58. Lahiri DK, Farlow MR, Nurnberger JI Jr, Greig NH. Effects of cholinesterase inhibitors on the secretion of beta-amyloid precursor protein in cell cultures. Ann N Y Acad Sci. 1997;826:416-21.

59. Cheng YS, Chen ZT, Liao TY, Lin C, Shen HC, Wang YH, et al. An intranasally delivered peptide drug ameliorates cognitive decline in Alzheimer transgenic mice. EMBO Mol Med. 2017;9(5):703-15.

60. Abraham CR, Mullen PC, Tucker-Zhou T, Chen CD, Zeldich E. Klotho is a neuroprotective and cognition-enhancing protein. Vitam Horm. 2016;101: 215-38.

61. Cummings J. Drug Development for Psychotropic, Cognitive-Enhancing, and Disease-ModifyingTreatments for Alzheimer's Disease. J Neuropsychiatry Clin Neurosci. 2020;appineuropsych20060152. https://doi.org/10.1176/appi. neuropsych.20060152. Online ahead of print. PMID: 33108950.

62. Cummings J, Mintzer J, Brodaty H, Sano M, Banerjee S, Devanand DP, et al. Agitation in cognitive disorders: international psychogeriatric association provisional consensus clinical and research definition. Int Psychogeriatr. 2015;27(1):7-17.

63. Fischer CE, Ismail Z, Youakim JM, Creese B, Kumar S, Nunez N, et al. Revisiting criteria for psychosis in Alzheimer's disease and related dementias: toward better phenotypic classification and biomarker research. J Alzheimers Dis. 2020;73(3):1143-56.

64. Robert P, Lanctot KL, Aguera-Ortiz L, Aalten P, Bremond F, Defrancesco M, et al. Is it time to revise the diagnostic criteria for apathy in brain disorders? The 2018 international consensus group. Eur Psychiatry. 2018;54:71-6.

65. Siddiqi SH, Taylor SF, Cooke D, Pascual-Leone A, George MS, Fox MD. Distinct symptom-specific treatment targets for circuit-based neuromodulation. Am J Psychiatry. 2020;177(5):435-46.

66. Mucke L, Selkoe DJ. Neurotoxicity of amyloid beta-protein: synaptic and network dysfunction. Cold Spring Harb Perspect Med. 2012;2(7):a006338

67. Weissberger GH, Melrose RJ, Narvaez TA, Harwood D, Mandelkern MA, Sultzer DL. (18)F-Fluorodeoxyglucose positron emission tomography cortical metabolic activity associated with distinct agitation behaviors in Alzheimer disease. Am J Geriatr Psychiatry. 2017;25(6):569-79.

68. Marshall GA, Monserratt L, Harwood D, Mandelkern M, Cummings JL, Sultzer DL. Positron emission tomography metabolic correlates of apathy in Alzheimer disease. Arch Neurol. 2007;64(7):1015-20.

69. Koppel J, Sunday S, Goldberg TE, Davies P, Christen E, Greenwald BS, et al. Psychosis in Alzheimer's disease is associated with frontal metabolic impairment and accelerated decline in working memory: findings from the Alzheimer's disease neuroimaging initiative. Am I Geriatr Psychiatry. 2014; 22(7):698-707.

70. Van Dam D, Vermeiren Y, Dekker AD, Naude PJ, Deyn PP. Neuropsychiatric disturbances in Alzheimer's disease: what have we learned from neuropathological studies? Curr Alzheimer Res. 2016;13(10):1145-64.

71. Grossberg GT, Kohegyi E, Mergel V, Josiassen MK, Meulien D, Hobart M, et al. Efficacy and safety of brexpiprazole for the treatment of agitation in Alzheimer's dementia: two 12-week, randomized, double-blind, placebocontrolled trials. Am J Geriatr Psychiatry. 2020;28(4):383-400.

72. Cummings JL, Lyketsos CG, Peskind ER, Porsteinsson AP, Mintzer JE, Scharre DW, et al. Effect of dextromethorphan-quinidine on agitation in patients with Alzheimer disease dementia: a randomized clinical trial. JAMA. 2015; 314(12):1242-54.

73. Herrmann N, Ruthirakuhan M, Gallagher D, Verhoeff N, Kiss A, Black SE, et al. Randomized placebo-controlled trial of nabilone for agitation in Alzheimer's disease. Am J Geriatr Psychiatry. 2019;27(11):1161-73.
74. Wang LY, Shofer JB, Rohde K, Hart KL, Hoff DJ, McFall YH, et al. Prazosin for the treatment of behavioral symptoms in patients with Alzheimer disease with agitation and aggression. Am J Geriatr Psychiatry. 2009;17(9):744-51.

75. Cummings J, Isaacson $\mathrm{S}$, Mills $\mathrm{R}$, Williams $\mathrm{H}$, Chi-Burris $\mathrm{K}$, Corbett $\mathrm{A}$, et al. Pimavanserin for patients with Parkinson's disease psychosis: a randomised, placebo-controlled phase 3 trial. Lancet. 2014;383(9916):533-40.

76. Ballard C, Banister C, Khan Z, Cummings J, Demos G, Coate B, et al. Evaluation of the safety, tolerability, and efficacy of pimavanserin versus placebo in patients with Alzheimer's disease psychosis: a phase 2, randomised, placebo-controlled, double-blind study. Lancet Neurol. 2018; 17(3):213-22.

77. Cummings J, Ballard C, Tariot P, Owen R, Foff E, Youakim J, et al. Pimavanserin: potential treatment for dementia-related psychosis. J Prev Alzheimers Dis. 2018;5(4):253-8.

78. Stern Y, Albert M, Brandt J, Jacobs DM, Tang MX, Marder K, et al. Utility of extrapyramidal signs and psychosis as predictors of cognitive and functional decline, nursing home admission, and death in Alzheimer's disease: prospective analyses from the predictors study. Neurology. 1994;44(12): 2300-7.

79. Lopez OL, Brenner RP, Becker JT, Ulrich RF, Boller F, DeKosky ST. EEG spectral abnormalities and psychosis as predictors of cognitive and functional decline in probable Alzheimer's disease. Neurology. 1997;48(6): $1521-5$.

80. Zhu CW, Grossman HT, Sano M. Why do they just sit? Apathy as a core symptom of Alzheimer disease. Am J Geriatr Psychiatry. 2019;27(4):395-405.

81. Cummings J. The neuropsychiatric inventory: development and applications. J Geriatr Psychiatry Neurol. 2020;33(2):73-84.

82. Rosenberg PB, Lanctot KL, Drye LT, Herrmann N, Scherer RW, Bachman DL, et al. Safety and efficacy of methylphenidate for apathy in Alzheimer's disease: a randomized, placebo-controlled trial. J Clin Psychiatry. 2013;74(8): 810-6.

83. Scherer RW, Drye L, Mintzer J, Lanctot K, Rosenberg P, Herrmann N, et al. The apathy in dementia methylphenidate trial 2 (ADMET 2): study protocol for a randomized controlled trial. Trials. 2018;19(1):46.

84. Ruthirakuhan MT, Herrmann N, Abraham EH, Chan S, Lanctot KL. Pharmacological interventions for apathy in Alzheimer's disease. Cochrane Database Syst Rev. 2018;5:CD012197.

85. Stella F, Radanovic M, Aprahamian I, Canineu PR, de Andrade LP, Forlenza OV. Neurobiological correlates of apathy in Alzheimer's disease and mild cognitive impairment: a critical review. J Alzheimers Dis. 2014;39(3):633-48.

86. Borges CR, Poyares D, Piovezan R, Nitrini R, Brucki S. Alzheimer's disease and sleep disturbances: a review. Arq Neuropsiquiatr. 2019;77(11):815-24.

87. Peter-Derex L, Yammine P, Bastuji H, Croisile B. Sleep and Alzheimer's disease. Sleep Med Rev. 2015;19:29-38.

88. Ju YE, Lucey BP, Holtzman DM. Sleep and Alzheimer disease pathology--a bidirectional relationship. Nat Rev Neurol. 2014;10(2):115-9.

89. Wang C, Holtzman DM. Bidirectional relationship between sleep and Alzheimer's disease: role of amyloid, tau, and other factors. Neuropsychopharmacology. 2020:45(1):104-20.

90. Herring WJ, Ceesay P, Snyder E, Bliwise D, Budd K, Hutzelmann J, et al. Polysomnographic assessment of suvorexant in patients with probable Alzheimer's disease dementia and insomnia: a randomized trial. Alzheimers Dement. 2020;16(3):541-51.

91. Scott LJ. Lemborexant: first approval. Drugs. 2020;80(4):425-32.

92. Zee PC, Vitiello MV. Circadian rhythm sleep disorder: irregular sleep wake rhythm type. Sleep Med Clin. 2009;4(2):213-8.

93. Holth JK, Fritschi SK, Wang C, Pedersen NP, Cirrito JR, Mahan TE, et al. The sleep-wake cycle regulates brain interstitial fluid tau in mice and CSF tau in humans. Science. 2019;363(6429):880-4.

94. Rosenberg PB, Drye LT, Porsteinsson AP, Pollock BG, Devanand DP,

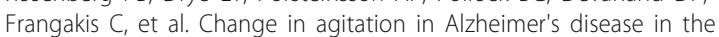
placebo arm of a nine-week controlled trial. Int Psychogeriatr. 2015; 27(12):2059-67.

95. Laursen DRT, Paludan-Muller AS, Hrobjartsson A. Randomized clinical trials with run-in periods: frequency, characteristics and reporting. Clin Epidemiol. 2019;11:169-84.

96. Huo X, Armitage J. Use of run-in periods in randomized trials. JAMA. 2020; 324(2):188-9.

97. Cummings JL, Tractenberg RE, Gamst A, Teri L, Masterman D, Thal LJ. Regression to the mean: implications for clinical trials of psychotropic agents in dementia. Curr Alzheimer Res. 2004;1(4):323-8. 
98. Enck P, Klosterhalfen S, Weimer K, Horing B, Zipfel S. The placebo response in clinical trials: more questions than answers. Philos Trans R Soc Lond Ser B Biol Sci. 2011;366(1572):1889-95.

99. Houston L, Probst Y, Yu P, Martin A. Exploring data quality management within clinical trials. Appl Clin Inform. 2018;9(1):72-81.

100. Boessen R, Knol MJ, Groenwold RH, Grobbee DE, Roes KC. Increasing trial efficiency by early reallocation of placebo nonresponders in sequential parallel comparison designs: application to antidepressant trials. Clin Trials. 2012;9(5):578-87.

101. Devanand DP, Pelton GH, Cunqueiro K, Sackeim HA, Marder K. A 6-month, randomized, double-blind, placebo-controlled pilot discontinuation trial following response to haloperidol treatment of psychosis and agitation in Alzheimer's disease. Int J Geriatr Psychiatry. 2011;26(9):937-43.

102. Devanand DP, Mintzer J, Schultz SK, Andrews HF, Sultzer DL, de la Pena D, et al. Relapse risk after discontinuation of risperidone in Alzheimer's disease. N Engl J Med. 2012;367(16):1497-507.

103. Koblan KS, Kent J, Hopkins SC, Krystal JH, Cheng H, Goldman R, et al. A nonD2-receptor-binding drug for the treatment of schizophrenia. N Engl J Med. 2020;382(16):1497-506.

104. Yang AC, Tsai SJ. New Targets for Schizophrenia Treatment beyond the Dopamine Hypothesis. Int J Mol Sci. 2017;18(8):1689. https://doi.org/10. 3390/ijms18081689. PMID: 28771182.

105. Zhao QF, Tan L, Wang HF, Jiang T, Tan MS, Tan L, et al. The prevalence of neuropsychiatric symptoms in Alzheimer's disease: systematic review and meta-analysis. J Affect Disord. 2016;190:264-71.

106. Orgeta V, Tabet N, Nilforooshan R, Howard R. Efficacy of antidepressants for depression in Alzheimer's disease: systematic review and meta-analysis. J Alzheimers Dis. 2017;58(3):725-33.

107. Browne CA, Lucki I. Targeting opioid dysregulation in depression for the development of novel therapeutics. Pharmacol Ther. 2019;201:51-76.

108. Price JB, Bronars C, Erhardt S, Cullen KR, Schwieler L, Berk M, et al. Bioenergetics and synaptic plasticity as potential targets for individualizing treatment for depression. Neurosci Biobehav Rev. 2018;90:212-20.

109. Rosenblat JD, Mclntyre RS, Alves GS, Fountoulakis KN, Carvalho AF. Beyond monoamines-novel targets for treatment-resistant depression: a comprehensive review. Curr Neuropharmacol. 2015;13(5):636-55.

110. Takakuwa M, Watanabe $Y$, Tanaka K, Ishii T, Kagaya $K$, Taniguchi $H$, et al. Antipsychotic-like effects of a novel phosphodiesterase 10A inhibitor T-251 in rodents. Pharmacol Biochem Behav. 2019;185:172757.

111. Tomasetti C, Montemitro C, Fiengo ALC, Santone C, Orsolini L, Valchera A et al. Novel pathways in the treatment of major depression: focus on the glutamatergic system. Curr Pharm Des. 2019;25(4):381-7.

112. Sevigny J, Suhy J, Chiao P, Chen T, Klein G, Purcell D, et al. Amyloid PET screening for enrichment of early-stage Alzheimer disease clinical trials: experience in a phase 1b clinical trial. Alzheimer Dis Assoc Disord. 2016;30(1):1-7.

113. Nakamura A, Kaneko N, Villemagne VL, Kato T, Doecke J, Dore V, et al. High performance plasma amyloid-beta biomarkers for Alzheimer's disease. Nature. 2018:554(7691):249-54

114. Schindler SE, Bollinger JG, Ovod V, Mawuenyega KG, Li Y, Gordon BA, et al. High-precision plasma beta-amyloid 42/40 predicts current and future brain amyloidosis. Neurology. 2019;93(17):e1647-e59.

115. Janelidze S, Mattsson N, Palmqvist S, Smith R, Beach TG, Serrano GE, et al. Plasma P-tau181 in Alzheimer's disease: relationship to other biomarkers, differential diagnosis, neuropathology and longitudinal progression to Alzheimer's dementia. Nat Med. 2020;26(3):379-86.

116. Cummings J, Feldman $\mathrm{HH}$, Scheltens $\mathrm{P}$. The "rights" of precision drug development for Alzheimer's disease. Alzheimers Res Ther. 2019;11(1):76

117. Chen J, Zook D, Crickard L, Tabatabaei A. Effect of phosphodiesterase (1B, 2A, 9A and 10A) inhibitors on central nervous system cyclic nucleotide levels in rats and mice. Neurochem Int. 2019;129:104471.

118. Potkin SG, Anand R, Fleming K, Alva G, Keator D, Carreon D, et al. Brain metabolic and clinical effects of rivastigmine in Alzheimer's disease. Int J Neuropsychopharmacol. 2001;4(3):223-30.

119. Nordberg A. PET studies and cholinergic therapy in Alzheimer's disease. Rev Neurol (Paris). 1999;155(Suppl 4):S53-63.

120. Dickerson BC. Functional magnetic resonance imaging of cholinergic modulation in mild cognitive impairment. Curr Opin Psychiatry. 2006;19(3): 299-306.

121. Harrison J, Minassian SL, Jenkins L, Black RS, Koller M, Grundman M. A neuropsychological test battery for use in Alzheimer disease clinical trials. Arch Neurol. 2007;64(9):1323-9.
122. Zygouris S, Tsolaki M. Computerized cognitive testing for older adults: a review. Am J Alzheimers Dis Other Dement. 2015;30(1):13-28.

123. Jutten RJ, Peeters CFW, Leijdesdorff SMJ, Visser PJ, Maier AB, Terwee CB, et al. Detecting functional decline from normal aging to dementia: development and validation of a short version of the Amsterdam IADL questionnaire. Alzheimers Dement (Amst). 2017;8:26-35.

124. Jutten RJ, Harrison J, de Jong FJ, Aleman A, Ritchie CW, Scheltens P, et al. A composite measure of cognitive and functional progression in Alzheimer's disease: Design of the Capturing Changes in cognition study. Alzheimers Dement (N Y). 2017;3(1):130-8.

125. Wang J, Logovinsky V, Hendrix SB, Stanworth SH, Perdomo C, Xu L, et al. ADCOMS: a composite clinical outcome for prodromal Alzheimer's disease trials. J Neurol Neurosurg Psychiatry. 2016;87(9):993-9.

\section{Publisher's Note}

Springer Nature remains neutral with regard to jurisdictional claims in published maps and institutional affiliations.
Ready to submit your research? Choose BMC and benefit from:

- fast, convenient online submission

- thorough peer review by experienced researchers in your field

- rapid publication on acceptance

- support for research data, including large and complex data types

- gold Open Access which fosters wider collaboration and increased citations

- maximum visibility for your research: over $100 \mathrm{M}$ website views per year

At BMC, research is always in progress.

Learn more biomedcentral.com/submissions 